\title{
Truncus arteriosus: successful surgical correction without the use of a valved conduit
}

\author{
KENNETH G REID,* MICHAEL J GODMAN, JANET E BURNS \\ From the Royal Hospital for Sick Children, Edinburgh
}

SUMMARY A new operation for the restoration of continuity between the right ventricle and pulmonary circulation in truncus arteriosus in infancy without the use of a tube graft is described. This was achieved by anastomosing the inferior margin of the detached confluent branch pulmonary arteries to the apex of a vertical infundibular ventriculotomy to form the posterior wall of the reconstructed right ventricular outflow tract. A patch of pericardium was used to form the anterior wall and complete the primary cardiac repair.

The surgical management of the infant with truncus arteriosus remains a challenge, although recent reports have indicated satisfactory results of corrective surgery in patients under one year of age. ${ }^{12}$ Major centres, however, still report high operative risks in small infants. ${ }^{3}$ The principles of repair and of intraoperative and postoperative management are becoming increasingly clear in this complex condition but invariably reports advise the placement of an appropriately sized Rastelli conduit, valved or otherwise, between the right ventricle and pulmonary arteries and accept the need for reoperation and further reconstruction at a later date. ${ }^{124}$ All conduits are liable to progressive stenosis, endocarditis, and valve failure if a valved conduit is used; reoperation carries its own important risk. ${ }^{56}$ Even if a second operation for conduit replacement is successful, it remains likely that a considerable number of children will require further operation especially after ten years with such a conduit. ${ }^{7}$

The preliminary work of Bailey $e t \mathrm{al}^{8}$ has led us to devise an operative technique that obviates the need for conduit placement in the common types of truncus arteriosus, allows for potential growth, and seems to have important advantages over conventional techniques while still retaining the advantages of anatomical correction. We have used this technique to correct truncus arteriosus in an infant weighing $3 \mathrm{~kg}$.

Requests for reprints to Dr Michael J Godman, Department of Cardiology, Royal Hospital for Sick Children, Sciennes Road, Edinburgh EH9 1LF.

^Present address: Division of Cardiac Surgery, King Faisal Specialist Hospital, Riyadh, Saudi Arabia.

\section{Case report}

A 10 week old infant was referred to the Royal Hospital for Sick Children, Edinburgh with a history of failure to thrive and recurrent chest infections. She was tachypnoeic with a respiratory rate of 75 per minute, there was intercostal indrawing, the peripheral pulses were all of full volume with a collapsing quality, and the blood pressure in the right arm was $100 / 30 \mathrm{~mm} \mathrm{Hg}$. On auscultation both heart sounds were single and there was a long, harsh grade $4 / 6$ systolic murmur and a grade $3 / 6$ early diastolic murmur that were both loudest at the lower left sternal edge. A chest $x$ ray showed cardiomegaly with a cardiothoracic ratio of $65 \%$ and increased pulmonary vascularity. Electrocardiographic examination showed biventricular hypertrophy with ST-T changes in the left lateral precordial leads.

The clinical features suggested a diagnosis of truncus arteriosus and this was confirmed on cardiac ultrasound examination which was interpreted as being in keeping with a type 1 truncus arteriosus and truncal valve regurgitation. After $\mathbf{4 8}$ hours of medical support and treatment with sedation, digoxin, frusemide, and ventilation she was taken to the operating theatre for repair of the defect.

\section{OPERATIVE PROCEDURE}

Figure la shows the anatomy of the vessels. There was no main pulmonary artery, both the right and left pulmonary arteries arose from the left lateral margin of the aortic root, the right artery being inferior in position and passing below the left vessel. Both arteries were extensively mobilised into both hila. The infant was cooled to $20-21^{\circ} \mathrm{C}$ while on 
(a)
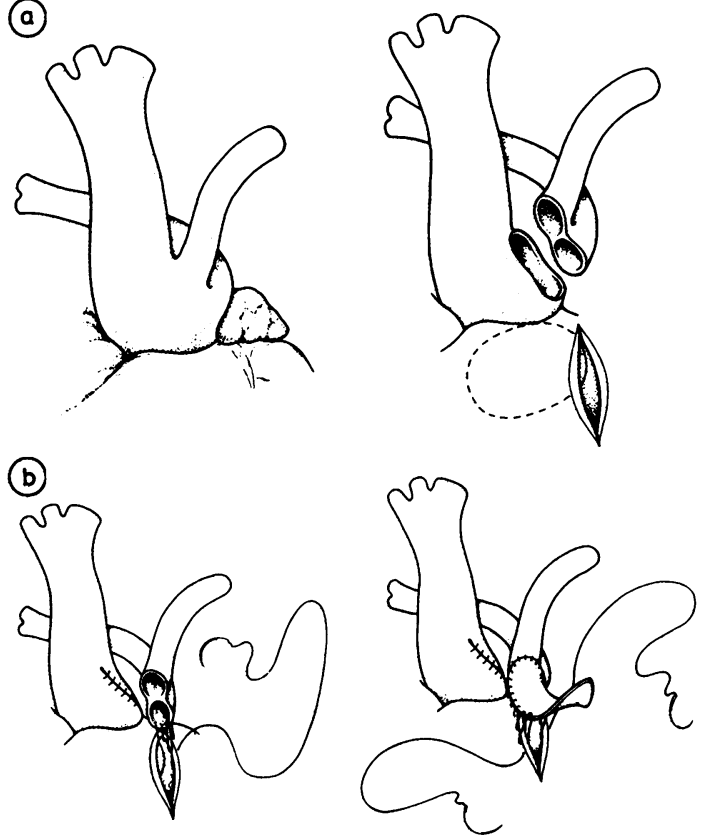

Fig 1 Diagrams showing restoration of continuity between the right ventricle and pulmonary circulation. (For details see text.

cardiopulmonary bypass; the pulmonary vessels were gently clamped to avoid bypass perfusion of the lungs and they were resected from the aorta. Then a cannula was manipulated into the left coronary ostium and cardioplegia was continued. A superior right ventriculotomy was made and through it the ventricular septal defect was closed. The aortotomy was repaired. The inferior margin of the right pulmonary artery was sewn to the superior margin of the ventriculotomy by means of a continuous to and fro Prolene suture. This suture was carried around one half of the inferior circumference of the right pulmonary artery opening, bringing it down on to the upper one quarter to one third of the ventriculotomy margin (fig lb). The anterior defect thus created was closed with a carefully tailored patch of xenograft bovine pericardium (Shiley Corporation). The procedure established generous egress from the right ventricle.

\section{POSTOPERATIVE COURSE}

The infant's postoperative course was uneventful. She was extubated 48 hours after operation and required no inotropic support. Postoperatively there was a residual grade $2 / 6$ to $3 / 6$ early diastolic murmur. Fifteen days after operation cardiac catheterisation was performed. The right ventricular systolic pressure was $55 \mathrm{~mm} \mathrm{Hg}$ and the pulmonary artery systolic pressure was $35 \mathrm{~mm} \mathrm{Hg}$, and a left ventricular peak systolic pressure was $90 \mathrm{~mm} \mathrm{Hg}$. Oximetry demonstrated a small residual left to right shunt of $1 \cdot 5: 1$. There was no pressure difference across the left ventricular outflow tract. A selective right ventricular angiogram demonstrated free egress of contrast into the pulmonary arteries with no important narrowing or obstruction (fig 2). Left ventricular angiography showed a small residual. ventricular septal defect at the lower margin of the

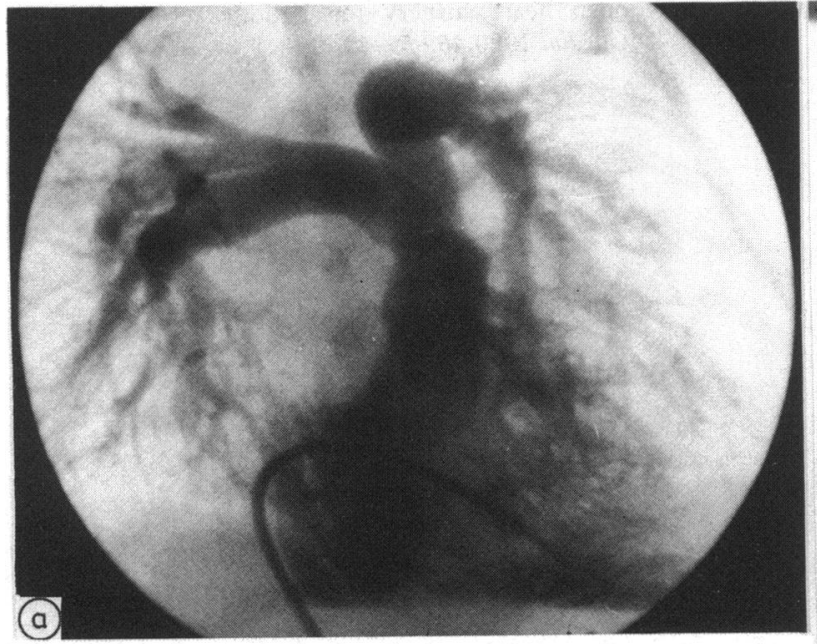

Fig 2 Postoperative right ventricular angiogram (anteroposterior and lateral views) demonstrating free egress of contrast into the pulmonary arteries with no important narrowing or obstruction.

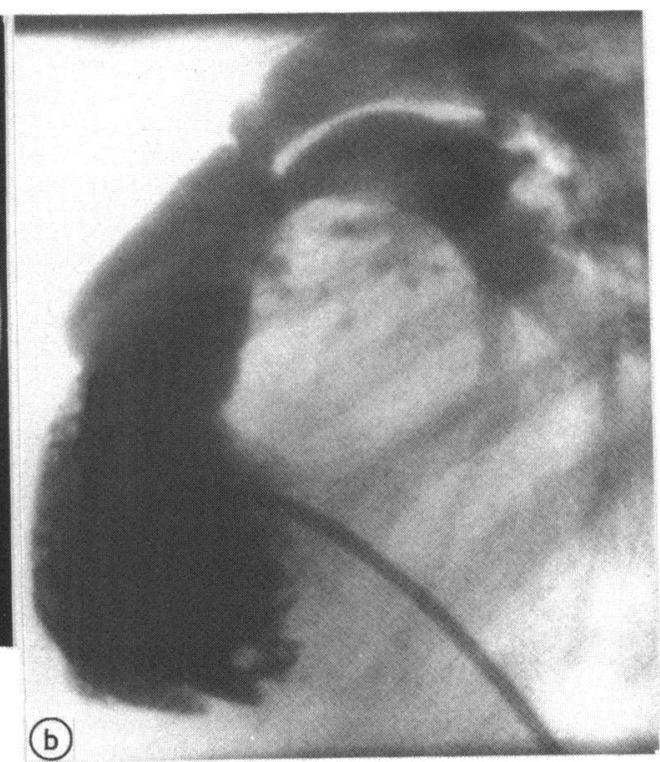


ventricular septal patch that had been inserted at operation. On aortography there was a mild to moderate degree of aortic valvar regurgitation.

\section{Discussion}

Orthodox right ventricular outflow tract reconstruction for other types of congenital heart disease is accomplished by transannular patching with pericardium or preclotted Dacron and follow up studies show an apparently normal propensity for growth. What is less certain is the efficacy of the valve leaflets and whether they are necessary for medium and long term success since adult cases can be symptom free in the face of chronic pulmonary valvar incompetence which, while not necessarily benign, is well tolerated. ${ }^{9}$ Our experience with this case agrees with that of others who have used non-valved conduits in this condition; we cannot agree with Bailey's conclusion that a competent pulmonary valve is required for short term survival. Moreover, the development in Bailey's case of a right ventricular outflow tract aneurysm within 40 days is strongly suggestive of important residual right ventricular hypertension that could have contributed to early death.

There are practical and theoretical advantages in applying this technique of right ventricular outflow tract reconstruction to types I and II truncus arteriosus. These include $(a)$ ease of operation, $(b)$ growth potential of the right ventricular/pulmonary artery junction, and $(c)$ avoidance of the acknowledged severe early and late complications of conduit placement in very young infants. We acknowledge the persistence of the native truncal valve regurgitation and the possibility that this could worsen with time.

\section{References}

1 Ebert PA, Turley K, Stanger P, Hoffman JI, Heymann MA, Rudolph AM. Surgical treatment of truncus arteriosus in the first six months of life. Ann Surg 1984;200:451-6.

2 Sharma AK, Brawn WJ, Mee RBB. Truncus arteriosus-surgical approach. $\mathcal{F}$ Thorac Cardiovasc Surg 1985;90:45-9.

3 Di Donato RM, Fyfe DA, Puga FJ, et al. Fifteen-year experience with surgical repair of truncus arteriosus. f Thorac Cardiovasc Surg 1985;89:414-22.

4 Spicer RL, Behrendt D, Crowley DC, et al. Repair of truncus arteriosus in neonates with the use of a valveless conduit. Circulation 1984;70:126-9.

5 Agarawal KC, Edwards WD, Puga FJ, Mair DD. Acute postoperative obstruction of extracardiac conduit due to separation of thin fibrous peel. Mayo Clinic Proc 1982;57:189-91.

6 Musumeci F, Piccoli GP, Dickinson DF, Hamilton DI. Surgical experience with persistent truncus arteriosus in symptomatic infants under 1 year of age. Report of 13 consecutive cases. $\mathrm{Br}$ Heart $\mathcal{f}$ 1981;46:179-85.

7 McGoon DC, Danielson GK, Puga FJ, Ritter DG, Mair DD, Illstrup DM. Late results after extracardiac conduit repair for congenital cardiac defects. Am $\mathcal{F}$ Cardiol 1982;49:1741-9.

8 Bailey LL, Petry EL, Doroshow RW, Jacobson JG, Wareham EE. Biologic reconstruction of the right ventricular outflow tract. Preliminary experimental analysis and clinical application in a neonate with type I truncus arteriosus. $\mathcal{F}$ Thorac Cardiovasc Surg 1981;82:779-84.

9 Fuster V, McGoon DC, Kennedy MA, Ritter D, Kirklin JW. Long term evaluation (12-22 years) of open heart surgery for Fallot's tetralogy. Am $\mathcal{J}$ Cardiol 1980;46:635-42. 